survival may yet lie in international agreement as if they do. De Klemm's (1984) view that a new world treaty on species conservation could and should function on the revenue from economically profitable species lowned by the community of nations) introduces a needless element of risk. There is no point in pretending the world can only afford to work a treaty that way: billion dollar space projects and defence budgets tell a different story.

\section{Sacrificing species gives no long-term benefit}

There is a flipside of the view that environmentalists hold the keys to our planet's future life. If, in capitulation to man's free use of his environment as part of his 'right to live', traditional conservationists were to abandon wildlife and put their paltry financial resources into economic development of the type now seemingly globally practised (i.e. unrestricted by ecological principles), the resulting sacrifice of species would have not the slightest long-term benefit, would do no more than postpone (and in some cases actually advance) the day when starvation and ruin returned. The conservation of species must therefore be seen not merely as the defence of a right and a freedom in itself, but as a model for many virtues, not least the management of the environment as the comerstone of all economic development. It is not a pursuit that can be put off until the crisis in Africa is over; it is something that needs to be both seen and done as part of the resolution of that crisis. The Red Data Books, guardians of our freedom, make a good place to start.

\section{Acknowledgments}

I am most grateful to my friends the staff of the ICBP International Secretariat and of the IUCN Conservation Monitoring Centre, also to T. M. Caro and A. C. Carter, for their comments on and discussions of this essay in draft. The views it expresses are, I should stress, entirely personal.

\section{References}

IUCN. 1980. World Conservation Strategy. International Union for Conservation of Nature and Natural Resources. Gland, Switzerland.

de Klemm, C. 1984. Protecting wild genetic resources for the future: the need for a world treaty. In National Parks, Conservation, and Development: The Role of Protected Areas in Sustaining Society (Eds J. A. McNeely and K. R. Miller), pp. 661-666. Smithsonian Institution Press, Washington DC.

Myers, N. 1979. The Sinking Ark. Pergamon Press, Oxford.

N. J. Collar, International Council for Bird Preservation, 219c Huntingdon Road, Cambridge CB3 ODL, UK.

\title{
Oryx: announcements and requests
}

The Society has renewed its publishing agreement with Blackwell Scientific Publications Ltd, which was undertaken for an initial period of three years in 1983. With the renewed agreement comes an increase in the number of Oryx pages-68 in each issue rather than 64 . We are also pleased to announce improvements in the publishing schedule, which mean that the news section of Oryx will be more up-to-date than has been possible in the past. Contributions for the 'News and views' and 'Briefly' sections are welcomed and should reach the Editor by:

24 January 1986 for the April issue

25 April 1986 for the July issue

28 July 1986 for the October issue

Species: a measure of man's freedom
22 October 1986 for the January 1987 issue.

The sporadic appearance of the Letters page is largely due to a dearth of contributions, and the Editor invites more of these, especially those of fewer than 300 words.

The move to new offices has provided us with the space to begin to build a picture library. The Editor is in great need of suitable illustrative material for the pages of Oryx-especially in the final stages of preparing each issue. If you have any suitable black-and-white or colour photographs or transparencies that you could donate to the collection they would be most gratefully received. 